\title{
PREVALENCE OF CARDIOVASCULAR RISK FACTORS AMONG ELDERLY BRAZILIANS OVER EIGHTY WITH ISCHEMIC STROKE
}

\author{
Alexandre Pieri, Mariana Spitz, Tania Oliveira Lopes, Claudia Garcia de Barros, \\ Marcelo Wood Faulhaber, Alberto Alain Gabbai, Miguel Cendoroglo-Neto
}

\begin{abstract}
Introduction: An ischemic stroke is usually a catastrophic event, mostly in the elderly. Cardiovascular involvement is the leading cause of ischemic stroke in this age population and hence the knowledge about its risk factors is important for the definition of specific policies of prevention. Purpose: To evaluate the prevalence of cardiovascular risk factors in patients with age equal to or above 80 in a hospital population with ischemic stroke. Method: Retrospective study of consecutive patients diagnosed with ischemic stroke admitted to a tertiary health facility. Results: From September 2004 to March 2006, 215 patients were studied. There was a female preponderance $(p<0.01)$. Among patients over eighty, $72 \%$ had hypertension and atrial fibrillation was more common among the oldest old $(p<0.01)$. Conclusion: Hypertension and atrial fibrillation should be treated aggressively in the elderly. Anticoagulants should be considered more often in these patients.
\end{abstract}

KEY WORDS: ischemic stroke, elderly over eighty, cardiovascular risk factors.

\section{Prevalência de fatores de risco cardiovasculares em idosos brasileiros acima de 80 anos e com acidente cerebrovascular isquêmico}

\begin{abstract}
Resumo - Introdução: Acidente cerebrovascular (AVC) isquêmico é geralmente um evento catastrófico, particularmente em idosos. Envolvimento cardiovascular é a principal causa de AVC na população desta faixa etária; dessa forma, o conhecimento acerca de seus fatores de risco é importante para a definição de políticas específicas de prevenção. Objetivo: Avaliar a prevalência de fatores de risco cardiovasculares em pacientes com idade igual ou superior a 80 anos numa população hospitalar tendo AVC isquêmico. Método: Estudo retrospectivo de pacientes consecutivos diagnosticados como AVC admitidos em um centro de saúde terciário. Resultados: De setembro de 2004 a março de 2006, 215 pacientes foram estudados. Houve predomínio do sexo feminino $(p<0,01)$. Entre os pacientes com mais de 80 anos, $72 \%$ tinham hipertensão e fibrilação atrial foi mais comum entre os idosos em idade mais avançada $(p<0,01)$. Conclusão: Hipertensão e fibrilação atrial devem ser tratados agressivamente em idosos. Anticoagulantes devem ser considerados mais freqüentemente nestes pacientes.
\end{abstract}

PALAVRAS-CHAVE: acidente cerebrovascular isquêmico, idosos acima de 80 anos, fatores de risco cardiovasculares.

Stroke is the leading cause of mortality in Brazil'. The most common subtype is ischemic stroke, responsible for about $85 \%$ of the cases ${ }^{2}$. The incidence and prevalence of ischemic stroke is closely related to cardiovascular risk factors ${ }^{3}$, which can be divided into modifiable and nonmodifiable. Modifiable risk factors include hypertension, diabetes, dyslipidemia, smoking, coronary artery disease and atrial fibrillation. Age is the most common non-modifiable risk factor for stroke - after age 55 , the risk of stroke doubles every decade ${ }^{4}$.
As the population ages worldwide, there has been an increasing number of patients over eighty diagnosed with stroke ${ }^{5}$. The prevalence of cardiovascular risk factors in this particular group can be different compared to other age ranges ${ }^{6}$. Primary and secondary prevention strategies in people over eighty depend on a better understanding of risk factors in this population.

This article discusses the prevalence of cardiovascular risk factors in hospitalized patients over eighty in São Paulo, Brazil.

Hospital Israelita Albert Einstein, São Paulo SP, Brazil.

Received 8 February 2008, received in final form 16 May 2008. Accepted 9 June 2008.

Dr. Alexandre Pieri - Rua Napoleão de Barros 874 / 14 - 04024-002 São Paulo SP - Brasil. E-mail: apieri@einstein.br 


\section{METHOD}

This is a retrospective study of consecutive cases of stroke patients admitted to Albert Einstein Hospital in São Paulo, Brazil. Patient approach followed the Stroke Protocol of the hospital's Neurology Primary Stroke Center, which is certified by the Joint Commission International. All patients were admitted to the First Aid Unit of the hospital, where they were included in the protocol. Clinical questionnaires were filled, including data on major cardiovascular risk factors.

Patients were considered hypertensive when there was previous history of systemic hypertension and/or current use of antihypertensive drugs ${ }^{7}$. Occurrence of diabetes was considered in patients whose fasting glucose was equal to or higher than $126 \mathrm{mg} / \mathrm{dL}$ and/or who were currently taking oral hypoglycemic agents or insulin ${ }^{8}$. Dyslipidemia was specified by total cholesterol higher than $200 \mathrm{mg} / \mathrm{dL}$ in previous exams and/or current use of hypolipidemic agents ${ }^{9}$. Smoking was determined by patients who were currently smoking or had refrained from smoking up to five years before the stroke ${ }^{10}$. Atrial fibrillation was defined by a previous ECG or ambulatory electrocardiography device and/or detection of the arrhythmia during inpatient stay ${ }^{11}$. Patients who were diagnosed with atrial fibrillation according to admission ECG were also enrolled. Coronary artery disease was determined by a suggestive clinical picture and/or confirmatory diagnostic exams ${ }^{12}$.

All patients with stroke were included and the prevalence of cardiovascular risk factors was compared among those younger than 65 , between 65 and 79 and over 80 years old. Univariate statistical analysis was performed to compare the information obtained in each group, using Fisher exact test or chi square, with a level of significance of $5 \%(p<0.05)$.

\section{RESULTS}

From September 2004 to March 2006, 215 patients diagnosed with stroke were enrolled in the study. From these, $78(36.3 \%)$ were eighty years old or over, 95 were between 65 and 79 (44.2\%) and 42 were younger than 65 (19.5\%).

\section{Sex}

Among patients younger than 65, 28 (67\%) were male. A higher percentage of men - $61 \%$ - was also observed in the group of patients between 65 and 79 years old. In the group over 80 , however, only 21 (27\%) were male, with a predominance of women in this age range. When compared to the age subgroups, there was a statistically significant preponderance of women in patients over $80(p<0.001)$.

\section{Hypertension}

Among all patients, 152 (71\%) were hypertensive. Among patients younger than 65, 24 (57\%) had hypertension, which was detected in $72(76 \%)$ of patients between 65 and 79 years old. 56 (72\%) of patients over eighty had this diagnosis. There was an increased proportion of hy- pertensive patients after 65 , but no significant difference comparing patients over 80 and those between 65 and $79(p=0.08)$.

\section{Diabetes}

Diabetes was found in 53 patients (25\%) of the entire group with stroke. There was a $17 \%$ rate among patients younger than 65 and $32 \%$ in those between 65 and 79. Among patients over 80,16 (20\%) had diabetes. There was no statistically significant difference concerning the prevalence of diabetes among the subgroups $(p=0.09)$.

\section{Dyslipidemia}

Dyslipidemia was determined in 31 (14.4\%) of the patients: $17 \%$ in patients younger than $65,7 \%$ in those between 65 and 79 and $7 \%$ in those over eighty. There was no statistically significant difference considering the prevalence of dyslipidemia between patients over and younger than $80(p=0.18)$.

\section{Smoking}

Among the total number of patients, 35 (16.3\%) were smokers - $8(19 \%)$ in the group younger than $65,10(11 \%)$ between 65 and 79 and only $4(5 \%)$ in the group over 80 . There was a trend toward a smaller percentage of smokers among the oldest when compared to patients younger than $80(p=0.05)$.

\section{Coronary artery disease}

Previous coronary artery disease was detected in 76 (35\%) of all patients. There were $6(14 \%)$ patients younger than 65, 34 (36\%) between 65 and 79 and 28 (36\%) over 80 with such diagnosis. There was a significant increase in the prevalence of coronary artery disease from 65 years old on ( $p=0.02)$, but no difference considering patients younger than and over 80 .

\section{Atrial fibrillation}

The diagnosis of atrial fibrillation was demonstrated in 35 (16.3\%) of the patients: $5 \%$ in those younger than $65,12 \%$ in the group between 65 and 79 and $26 \%$ over 80 . There was a statistically significant increase of atrial fibrillation in the latter group $(\mathrm{p}<0.01)$.

\section{DISCUSSION}

There are few reports describing the relationship between cardiovascular risk factors and stroke which focus specifically on an older population; particularly patients over eighty ${ }^{6,13}$. Our hospital covers a segment of the population, with a higher life expectancy. When evaluating all patients enrolled in the study, we noticed that $80 \%$ were elderly and $36 \%$ were 80 years old or over. Stroke in such patients is frequent in our hospital. 
Stroke is classically considered a disease with a higher prevalence in men, though there appears to be a higher prevalence in women after $80^{13}$. In our study among those older than 80 there was a predominance of females diagnosed with stroke. This is probably related to a higher life expectancy of women when compared to men. This female predominance is important when we consider that acute therapy for stroke, drugs used for primary and secondary prevention and invasive procedures may have a different profile of risks and benefits in men and women ${ }^{14-16}$. Our findings emphasize the need of further studies to assess in detail elderly women with stroke.

Hypertension is the main risk factor for stroke and its prevalence rises with age ${ }^{7,17}$. We showed an increased number of hypertensive patients with aging when we compared the groups younger than 65 and between 65 and 79 year old, but on the other side, there was no difference in the percentage of hypertensive patients when comparing patients between 65 and 79 and those over 80. Our sample does not allow further conclusions, but hypertension may have a less direct effect in stroke patients over 80 .

Diabetes is considered an independent risk factor for stroke recurrence and affects approximately $8 \%$ of the adult population ${ }^{8}$. Among stroke patients, the prevalence of diabetics ranged from 15 to $33 \%$ in previous studies ${ }^{18,19}$. In our study, one fourth of the patients had diabetes. There was a higher percentage in the group between 65 and 79 , followed by a reduction in those over 80 . The morbidity and mortality associated with diabetes may partially explain such smaller percentage.

The impact of dyslipidemia as a risk factor for stroke seems to be less then for cardiac disease ${ }^{20}$. A recent clinical trial demonstrated a reduction in stroke recurrence with the use of statins in high doses ${ }^{21}$. In our analysis we observed a low incidence of dyslipidemia, particularly in patients aged 65 or over.

There is strong and convincing evidence that smoking is one of the most important independent risk factors for stroke ${ }^{10,22}$. Previous studies demonstrated that the increase in the risk of stroke related to smoking does not depend on age, sex or ethnical group ${ }^{10,22,23}$. In our study there was a trend towards a smaller prevalence of smokers in patients over 80 . The association of smoking with severe respiratory diseases and cancer may explain, in part, such finding.

Coronary artery disease shares cardiovascular risk factors with atherosclerotic disease of large cerebral arteries. The coexistence of coronary artery disease, peripheral artery disease and stroke in the same patient has been described increasingly more frequently ${ }^{24}$. Coronary artery disease is the main cause of heart failure, which, when se- vere, constitutes an important cardiac source of cerebral emboli ${ }^{25}$. Heart failure raises in 2 to 3 times the risk of ischemic stroke recurrence, being responsible for up to $10 \%$ of those in the USA ${ }^{25,26}$. Age is a well known non-modifiable risk factor for coronary artery disease. Our study showed a statistically significant increase in the prevalence of coronary artery disease in patients between 65 and 79 years old, when compared to those younger than 65 . There was no difference when comparing the group between 65 and 79 and that over 80 . In our study $36 \%$ of ischemic stroke patients and age higher than 65 had concomitant coronary artery disease. Preventive health measures should aim to reduce the incidence of both conditions.

Persistent and paroxysmal atrial fibrillation represent important ischemic stroke predictors ${ }^{27}$. There are estimates that over 2 million people have atrial fibrillation in the USA. Aging is directly associated with an increased number of cases of atrial fibrillation, which constitutes the most common arrhythmia in the elderly ${ }^{27}$. Atrial fibrillation was the most important risk factor for cardioembolic ischemic stroke in a study of octogenarians ${ }^{13}$. Our study show a higher percentage of atrial fibrillation in the group of patients between 65 and 79, when compared to those younger than 65 . There was also a statistically significant difference in the percentage of patients over 80 with atrial fibrillation when compared to those between 65 and $79(p<0.01)$. Our results show an increase percentage of atrial fibrillation patients with aging, as we have previously described. Patients over 80 had twice the chance of atrial fibrillation when compared to those between 65 and 79 years old. This finding suggests a strong impact of atrial fibrillation in patients over 80 . After a first stroke, the use of oral anticoagulants leads to a $68 \%$ reduction of the relative risk of recurrence ${ }^{28,29}$. On the other hand, advanced age is a predictor of cerebral hemorrhage secondary to the use of oral anticoagulants ${ }^{30}$. Studies evaluating predisposing risk factors for hemorrhage in patients under oral anticoagulants may help identify a safer therapeutic indication in the elderly with atrial fibrillation ${ }^{6}$.

In conclusion, the high prevalence of cardiovascular risk factors in our patients over eighty emphasizes the requirement of effective preventive actions in this population. The high prevalence of atrial fibrillation suggests that the administration of oral anticoagulants should be considered more frequently.

\section{REFERENCES}

1. Minelli C, Fen LF, Minelli DPC. Stroke incidence, prognosis, 30-day, and 1-year case fatality rates in Matão, Brazil: a population-based prospective study. Stroke 2007;38:2906-2911.

2. American Heart Association. Heart disease and stroke statistics - 2004 update. Available from: http: / / www.americanheart.org/downloadable/ heart / 1079736729696 HDSStats2004UpdateREV3-19-04.pdf 
3. Sacco RL, Adams R, Albers G, et al. Guidelines for prevention of stroke in patients with ischemic stroke or transient ischemic attack: a statement for healthcare professionals from the American Heart Association/ American Stroke Association Council on Stroke: co-sponsored by the Council on Cardiovascular Radiology and Intervention. Stroke 2006;37:577-617.

4. Brown RD, Whisnant JP, Sicks JD, O'Fallon WM, Wiebers DO. Stroke incidence, prevalence, and survival: secular trends in Rochester, Minnesota, through 1989. Stroke 1996;27:373-380.

5. Wolf PA, D'Agostino RB, $\mathrm{O}^{\prime} \mathrm{Neal} \mathrm{MA}$, et al. Secular trends in stroke incidence and mortality: the Framingham Study. Stroke 1992;23:1551-1555.

6. Mant J, Hobbs F, Fletcher K, et al. Warfarin versus aspirin for stroke prevention in an elderly community population with atrial fibrillation (the Birmingham Atrial Fibrillation Treatment of the Aged Study, BAFTA): a randomised controlled trial. Lancet 2007 11;370:493-503.

7. Chobanian AV, Bakris GL, Black HR, et al. The seventh report of the Joint National Committee on prevention, detection, evaluation, and treatment of high blood pressure: the JNC 7 report. JAMA 2003;289:2560-2571.

8. American Diabetes Association: clinical practice recommendations. Diabetes Care 2004;27(Suppl):S1-S143.

9. Expert panel on detection, evaluation, and treatment of high blood cholesterol in adults. Executive summary of the third report of the National Cholesterol Education Program (NCEP) (Adult Treatment Panel III). JAMA 2001;285:2486-2497.

10. Wolf PA, D'Agostino RB, Kannel WB, Bonita R, Belanger AJ. Cigarette smoking as a risk factor for stroke: the Framingham study. JAMA 1988;259:1025-1029.

11. Adjusted-dose warfarin versus low-intensity, fixed-dose warfarin plus aspirin for high-risk patients with atrial fibrillation: stroke prevention in atrial fibrillation III randomised clinical trial. Lancet 1996;348:633-638.

12. Antman EM, Anbe DT, Armstrong PW, et al. ACC/AHA guidelines for the management of patients with ST-elevation myocardial infarction. Circulation 2004;110:e82-292.

13. Rojas JI, Zurrú MC, Romano M, Patrucco L, Cristiano E. Acute ischemic stroke and transient ischemic attack in the very old risk factor profile and stroke subtype between patients older than 80 years and patients aged less than 80 years. Eur J Neurol 2007;144:895-899.

14. Kjeldsen SE, Kolloch RE, Leonetti G, et al. Influence of gender and age on preventing cardiovascular disease by antihypertensive treatment and acetylsalicylic acid. The HOT study. Hypertension Optimal Treatment. J Hypertens 2000;18:629-642.

15. North American Symptomatic Carotid Endarterectomy Trial Collaborators. Beneficial effect of carotid endarterectomy in symptomatic patients with high-grade carotid stenosis. N Engl J Med 1991;325:445-453.
16. The National Institute of Neurological Disorders and Stroke rt-PA Stroke Study Group. Tissue plasminogen activator for acute ischemic stroke. N Engl J Med 1995;333:1581-1587.

17. Pires LS, Gagliardi RJ, Gorzoni ML. Estudo das freqüências dos principais fatores de risco para acidente vascular cerebral isquêmico em idosos. Arq Neuropsiquiatr 2004;62:844-851.

18. Karapanayiotides T, Piechowski-Joswiak B, van Melle G, Bogousslavsky J, Devuyst G. Stroke patterns, etiology, and prognosis in patients with diabetes mellitus. Neurology 2004;62:1558-1562.

19. Woo D, Gebel J, Miller R, et al. Incidence rates of first-ever ischemic stroke subtypes among blacks: a population based study. Stroke 1999;30:2517-2522.

20. Amarenco P, Tonkin AM. Statins for stroke prevention: disappointment and hope. Circulation 2004;109:III-44-III-49.

21. The Stroke Prevention by Aggressive Reduction in Cholesterol Levels (SPARCL) Investigators. High-dose atorvastatin after stroke or transient ischemic attack. N Engl J Med 2006;355:549-559.

22. Shinton R, Beevers G. Meta-analysis of relation between cigarette smoking and stroke. BMJ 1989;298:789-794.

23. Wannamethee SG, Shaper AG, Whincup PH, Walker M. Smoking cessation and the risk of stroke in middle-aged men. JAMA 1995;274:155-160.

24. Bartholomew JR, Olin JW. Pathophysiology of peripheral arterial disease and risk factors for its development. Clev Clin J Med 2006;73 (Suppl):S8-S14.

25. Pfeffer MA, Braunwald E, Moyé LA, et al. Effect of captopril on mortality and morbidity in patients with left ventricular dysfunction after myocardial infarction: results of the Survival and Ventricular Enlargement Trial. N Engl J Med 1992;327:669-677.

26. Visser CA, Kan G, Meltzer RS, Lie KI, Durrer D. Long term follow-up of left ventricular thrombus after acute myocardial infarction: a two-dimensional echocardiographic study in 96 patients. Chest 1984;86:532-536.

27. Atrial Fibrillation Investigators. Risk factors for stroke and efficacy of antithrombotic therapy in atrial fibrillation: analysis of pooled data from five randomized controlled trials. Arch Intern Med 1994;154:1449-1457.

28. Hylek EM, Skates SJ, Sheehan MA, Singer DE. An analysis of the lowest effective intensity of prophylactic anticoagulation for patients with non-rheumatic atrial fibrillation. N Engl J Med 1996;335:540-546.

29. Cabral NL, Volpato D, Ogata TR, Ramirez T, Moro C, Gouveia S. Fibrilação atrial crônica, AVC e anticoagulação: sub-uso de warfarina? Arq Neuropsiquiatr 2004;62:1016-1021.

30. Campbell NR, Hull RD, Brant R, Hogan DB, Pineo GF, Raskob GE. Aging and heparin-related bleeding. Arch Internal Med 1996;156:857-860. 